\title{
Expressive Arts Therapy with Chinese Calligraphy Elements as a Working Approach
}

\author{
中國書法元素融入表達藝術治療作實踐模式 \\ Esther Yau Ching Nam \\ The University of Hong Kong, Hong Kong, China
}

\begin{abstract}
The properties of Chinese calligraphy and its beauty have captured the imagination and expression of artists throughout the Eastern history. Although some in the Chinese world still practice Chinese calligraphy as an art today, many first encounter it as part of the literacy education in primary school curriculum. Repetitive mimicking is often emphasized in the process without much creative element. As a Chinese calligrapher who aspires to reflect on the creative aspect of the art form, this author chose to integrate elements of Chinese calligraphy with other art modalities in work with teenagers in school setting. This article will look at applying Chinese calligraphy elements to a framework called the expressive therapies continuumin group therapy setting.
\end{abstract}

Keywords: Chinese calligraphy, Expressive therapies continuum, Expressive arts therapy

\section{摘要}

中國書法的特性及其美麗捕捉了整個東方歷史藝術家的想像力和表達。在華人社會中有 不少人仍將中國書法視作為藝術來實踐，但許多初次接觸中國書法卻是小學課程中練字 課程内。在教學過程中通常會強調重複模仿，而沒有太多創意元素。作為一位反思藝 術形式創造性方面的中國書法愛好者，作家選擇將中國書法的元素與其他藝術形式相 結合，並與學校中的青少年一起實踐。本文將探討如何將中國書法元素應用於團體治療 中，並探討在表達性治療連續系統框架下的應用。

\section{關鍵詞：中國書法，表達性治療連續系統，表達藝術治療}

\section{Introduction}

There are many skills and techniques that we can learn for making art. However, when we bring an art medium into expressive arts therapy sessions, the aim is no longer only fostering skill perfection; instead, therapists emphasize the power of expression, creativity, and imagination of the medium's properties. In this article, I will share how I incorporate Chinese calligraphy elements in expressive arts therapy (ExAT) sessions with teenagers.

Chinese calligraphy is an ancient art form traced back to the first century that involves calligraphic handwriting of Chinese characters with the use of a soft-tipped brush. Numerous studies focus on the therapeutic effects on trainings in imitating models of script. Brown and Ryan (2003) found that the movement of mastering a soft-tipped 
brush helps the practitioners become aware of their present moment experiences through increasing awareness of kinesthetic movement and internal rhythm. Kao, Lam, Robinson, and Yen (1989) found that people who regularly practiced Chinese calligraphy had decreased respiration rate, heartrate, and blood pressure. In another experiment conducted by Kao, Gao, Wang, Cheung, and Chiu (2000), spatial ability, spatial relations, and abstract reasoning were promoted through calligraphy training.

Chinese calligraphy is usually taught in one to two lessons as part of aliteracy curriculum in Hong Kong primary school settings, but it is mostly neglected in art education curriculum. In this limited number of lessons, simple brush holding skill is taught. Traditional methods of teaching place much emphasis on standardized penmanship; therefore, many students see writing Chinese calligraphy as a part of their homework task, like finishing a copy book, instead of seeing it as an art-creating process.

My own journey with Chinese calligraphy as a hobby was long and slow, beginning with traditional script learning and then learning different types of writing styles, from the use of checkered paper to a plain, long rice-paper rolls. The latter became an esthetic way to compose Chinese characters by juxtaposing components and arrangement of the characters and emptiness on the art piece. I realized that this process is not only a copying process that requires calligraphy skills, but is also an artistic process that synthesizes esthetic elements, allows creativity, and brings insights.

As part of my own search to understand Chinese calligraphy beyond the bounds of our standard education, I have started to apply more Chinese calligraphy elements in the art-making process in ExAT. ExAT is known as multimodality therapeutic work that engages the visual arts, dance and movement, drama, poetry, and music creative process. According to Knill, Levine, and Levine (2005), the primary focus is the variety of sensory channels and imagination modalities of each art modality. To better connect different art modalities in the sessions, I turned to the expressive therapies continuum (ETC) for a framework that facilitates my own observation of the therapeutic functions and healing qualities of Chinese calligraphy in a structured way. ETC offers a common language for different approaches in creative arts therapy and other professionals to communicate the therapeutic goals, methods, and effects.

\section{Expressive Therapies Continuum}

The ETC, according to Hinz (2015), offers a method for conceptualizing how and why particular art interactions can be therapeutic. The left and right sides of the ETC diagram are paralleled with the left and right brain hemisphere functions, respectively. The left side of the ETC includes cognitive, perceptual, and sensory aspects, which mainly help with the understanding and use of language, mathematics, and logic. The other side of the ETC framework includes symbolic, affective, and kinesthetic components, which are responsible for creativity, imagination, holistic thinking, and feelings.

The three levels in ETC represent a developmental sequence of image forming and information processing. As shown in Figure 1, the bottom level includes the kinesthetic (K) and sensory (S) components. The middle level includes the perceptual (P) and 


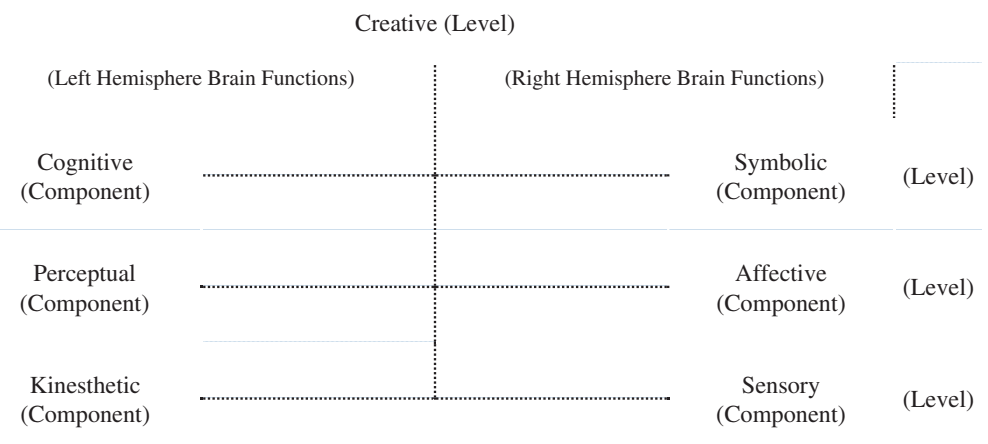

FIGURE 1 | The expressive therapies continuum (Hinz, 2015).

affective (A) components. The top level includes a more complex and sophisticated information processing and symbolic representation, which are the cognitive and symbol components. Each component has its own healing and emergent functions.

\section{Chinese Calligraphy in Therapy Setting}

As a therapist working in school settings, I have the chance to incorporate Chinese calligraphy elements into the therapy groups in secondary school setting.

\section{Bottom level: Kinesthetic and sensory components}

According to Hinz (2015), the kinesthetic component is the basic level and the first mode of expression; it is a preverbal component that develops during early childhood before language development. Energy/arousal stimulation and tension reduction are the major healing dimensions of the kinesthetic component. The sensory component refers to information processing that involves only sensation without cognitive overlay, which includes visual, auditory, gustatory, olfactory, and tactile channels.

Chinese calligraphy is an art modality filled with sensory stimulation and involves some kinesthetic components. Tian (提按) refers to the mastery of brush lifting and pressing through experience of multiple-layered contrasts, namely light and heavy, soft and hard, dense and pale, dry and wet (Yang, 2010). Such contrasts were believed to be helpful in sensitizing participants, as it would present unfolded spectrums of sensory stimuli to process. Another calligraphic idea, Hangqi (行氣), requires the writer to move in a steadily rhythmic continuation with a contemplative mind in order to produce calligraphy work of esthetic cohesion (Chen, 1997).

Participants in therapy groups in schools are usually handpicked or directed by teachers, as they are perceived as having emotional, social, or behavioral problems in schools. Therefore, not everyone knows each other in advance nor has a high motivation to join the sessions. Groups are expected to face participant's hesitation and insecurity due to the stigmatization. Therefore, releasing energy and decreasing social tensions by activities with sensory and kinesthetic components are major consideration in the first few sessions. 
In the group therapy setting for teenagers, I borrowed the calligraphic idea, Hangqi, and turned that into some kinesthetic games. Instead of using brushes and papers to start with, we used big floor sweepers and the classroom floor, which imitated the brush-writing process in Chinese calligraphy. Participants were divided into teams, and they had to move the floor sweepers on the floor with multipoints to reach in the game, drawing and writing on floor with different speed and size. These full-body movements with alternate speeds, tensions, paces, and levels help release participants' energy and break social awkwardness. By guiding participants to focus on their movements, the activities help participants shift attention away from insecurity in social situations that bring tensions.

\section{Middle level: Perceptual and affective components}

Hinz (2009) described in her research papers that the perceptual component require clients to use visual imagery to represent their internal experiences. The focus of the perceptual component is on the formal elements of visual expression such as line and shape. Emphasis on form or structure characteristics helps contain the affect and emotions. Affective component refers to the emotion expression while interacting with arts media. Colors are a prominent way to express one's feelings.

On this level, Chinese calligraphy carries a lot perceptual components in its practice. For example, Lingmo (臨摹) has the repetitive mimicking process, which requires practitioners to first observe how the lines and emptiness are arranged, which they later follow. Lingmo requires one to be both xingsi (形似, similar in form and shape) and shensi (神似, similar in spirit) (Yang, 2010). However, the mimicking process does not leave much space for expressions of personal feelings; whereas practitioners with more skills enjoy more room for expression of thoughts and feelings, as they have the foundation of knowing how to use different styles and strengths to show their feelings.

In therapy group for teenagers, the perceptual and affective components are both common and important in sessions. Malekoff and Kolodny (1991) claimed that loneliness is a suitable topic to be addressed in the context of adolescent group therapy. By normalizing the experience in group therapy, loneliness could be alleviated through the group process. Besides, teenagers tend to exaggerate the difference of whom they seldom interact with and overstress the behavioral and thinking difference. As mentioned by Erikson (1963, p. 262), "for adolescent...help one another temporarily through much discomfort by forming cliques and stereotyping themselves, their ideals, and their enemies." Therefore, instead of a direct lecture of "appropriate" behavior and misconceptions, the art-creating process allows teenagers to organize and reflect. With the help of therapist to create a safe space to share, genuine conversation and effective communication are intended to promote to reduce loneliness and build connections with each other.

In my therapy group for teenagers, they initially use paints with colors instead of purely black ink. A large shared paper is laid out on the floor. Participants are encouraged to begin by drawing basic visual elements, namely points, lines, and shapes, that represent themselves in a circle. We called it their "comfort zones." Students found using 
colors help facilitate sharing of a wider expression on thoughts and feelings of self. By building a safe and trusted atmosphere in the group, participants actively observe and mimic what others draw (Lingmo). Sharing was optional, participants were invited to draw a line from their part to the sharer's part if they had shared similar feelings and understanding instead of commenting. In my observation, participants make connections with others by sharing information about of themselves and discovering commonalities. On top of making new connections, the activity also facilitated the reimagining of their relationships with others in the group, beyond existing connections developed prior to the interventions, and broke their stereotypes of themselves and loneliness.

To sum up this level, the use of other art forms is more dominant than the use of Chinese calligraphy on this level. It was suggested that further implementation and research could be done on the application and healing function of Chinese calligraphy specifically on these levels.

\section{Top level: Cognitive and symbolic components}

According to Hinz (2009), the cognitive component involves more thinking, abstract concepts, and complex steps in art making. The healing function of the cognitive component supports greater executive functioning and increases planning and problemsolving abilities as well as decision-making skills. The symbolic component emphasizes intuitive concept formation (i.e., expression of symbolic, personal meaning in visual images, music, and poems with metaphoric representation). According to Hinz, healing takes place when participants have the ability to understand and benefit from personal and universal symbolic meaning. Such meaning mastery promotes psychological growth through consolidation and strengthening of personal meaning.

In my practice, I found Chinese calligraphy requires strong cognitive and symbolic processing in the writing process. In Xuanpain (選篇), a calligrapher selects a piece of workfrom a collection of pieces by various predecessors, as the creation of components were normally rearrangement and transformation based upon pictographic components that the participants would have seen before (Chen, 1994). Xianpain is one of the strongest procedures and require cognitive skills. Meanwhile, the practice of Jiezi (結字) is a perfect manifestation of symbolization. Jiezi is the esthetic way of composing a Chinese character by juxtaposing components (Qiu, 1995). Chinese characters, unlike those of other languages, are developed as logograms, which are highly stylized and simplified pictures of material objects, or built by blocks of compound characters as pictophonetic characters. Therefore, the subtle symbolic meaning changes when people build a character with different speed, strength, shapes, and emptiness (布白).

In therapy group for teenagers, the cognitive component becomes important when participants are able to generalize from one tangible experience to another. As mentioned in Hinz's (2009) book on ETC, the symbolic component manifests itself with a greater acceptance of self, which is another strong need suggested by Erikson (1963) about the identity issue of youth. 
In the sessions, I introduced the Chinese characters and how they evolved from pictographic elements to a symbol/Chinese character, so they can create symbolic character by signifying their discoveries, insights, and reflection they gained in the group. In one of the groups in the anti-bullying program, students came up with various pictographic elements (Figure 2). The process of symbol creation required cognitive summarization of experiences. Some participants experimented with the symbols with deliberation in esthetic and communicational sense (Figure 3).

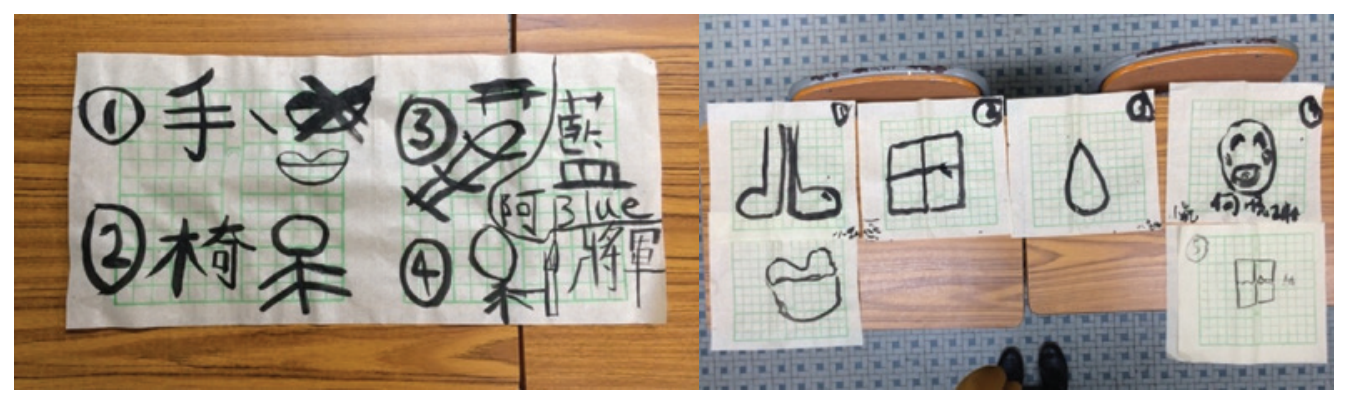

FIGURE 2 | Juxtaposition of four symbols—-body part, tool, place. and people.

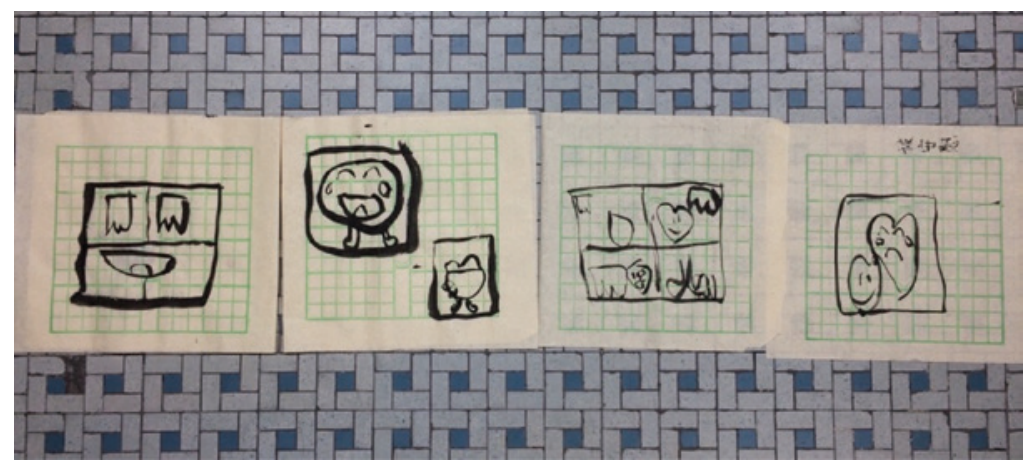

FIGURE 3 | Process of extracting and consolidating the core message.

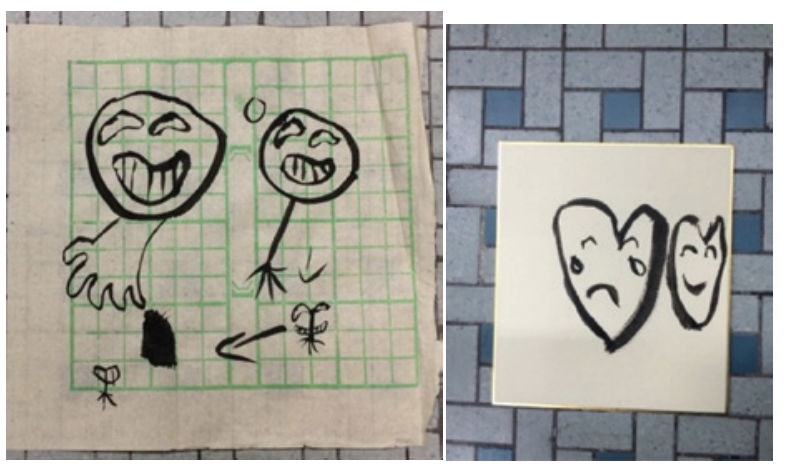

FIGURE 4 | Personal meaningful symbols of the participants. 


\section{Conclusion}

Chinese calligraphy had unique characteristics that resulted in a variety of therapeutically relevant effects. Under the ETC framework, the processing levels of the art form could be observed in detail. In this context, the third level-cognitive and symbolic components - was best facilitated and promoted by the direct use of Chinese calligraphy elements. In the other two levels, the use of different art forms is needed, in order to assist the manifestation of those components.

The difference when applying Chinese calligraphy in art training and therapy was discussed as well. A shift from the text/phrase composition to a word composition allowed more space for creativity. In the symbol-creating process, all group members were fully engaged in the ink- and brush-writing time. They were allowed the intuitive concept to help create basic forms instead on focusing on the art and skill of writing techniques. These instructions and procedures successfully shifted the attention from standardized penmanship judgment to a creative self-discovery and acceptance process.

The article suggests the possibility of applying Chinese calligraphy as a holistic approach in therapeutic setting. The discussion challenges therapists to explore a broad application of Chinese calligraphy in treatments. However, it is a pioneering attempt, and thus, more opportunities for further work or research are encouraged.

\section{About the Author}

Esther Yau Ching Nam is a practicing registered Creative Arts Therapist in educational psychology service unit in Hong Kong Tung Wah Group of Hospitals. Esther is dedicated to applying expressive arts therapy in social-emotional education, counselling and therapy service especially in educational settings. Esther is also a registered facilitator of Circle of Security ${ }^{\circledR}$, Tuning in to Kids and SoulCollage ${ }^{\circledR}$.

\section{References}

Brown, K. W., \& Ryan, R. M. (2003). The benefits of being present: Mindfulness and its role in psychological well-being. Journal of Personality and Social Psychology, 84(4), 822-848.

Chen, Z. L. (1994). Calligraphy. Vol. 1 \& Vol. 2. Taipei: Chien Hong.

Chen, Q. Z. (1997). A study of frames of calligraphy and styles of calligraphy. Taipei: Hua Cheng.

Erikson, E. H. (1963). Childhood and society. NewYork: Norton.

Hinz, L. D. (2009). Expressive therapies continuum: A frame-work for using art in therapy. New York: Routledge.

Hinz, L. D. (2015). Expressive therapies continuum: Use and value demonstrated with case study. Canadian Art Therapy Association Journal, 28, 1-2, 43-50.

Kao, H. S. R., Gao, D. G., Wang, M. Q., Cheung, H. Y., \& Chiu, J. (2000). Chinese calligraphic handwriting: Treatment of cognitive deficiencies of Alzheimer's disease patients. Alzheimer's Reports, 3, $281-287$.

Kao, H. S. R., Lam, P. W., Robinson, L., \& Yen, N. S. (1989). Psychophysiological Changes Associated with Chinese Calligraphy. In P. Plamondon, C. U. Suen, \& M. L. Simner (Eds.), Computer recognition and human production of handwriting (pp. 349-381). Singapore: World Scientific Publishing.

Knill, P. J., Levine, E. G., Levine, S. K. (2005). Principles and practice of expressive arts therapy: Toward a therapeutic aesthetics. London/Philadelphia, PA: Jessica Kingsley.

Malekoff, A., \& Kolodny, R. L. (1991). Memories and memory building: Reflections on group work with the lonely child. Social Work with Groups, 14(1), 87-103. 
Qiu, Z. Z. (1995). The composition of Zhangfa. Calligraphy arts and appreciation. Taipei: Asiapac.

Yang, P. H. (2010). Soundless Music: The Interplay of Spatiality and Musicality in Chinese Calligraphy. Journal of National Taiwan Normal University, 55(2), 117-136. 